\title{
Neurosurgery in a Case of Suspected Prion Disease: Challenges Faced
}

\author{
Anooja Abdul Salam ${ }^{1, \odot}$ Arvind Dubey ${ }^{2,3, \odot}$ \\ ${ }^{1}$ Department of Neurosurgery, Royal Hobart Hospital, Hobart, \\ Tasmania, Australia \\ ${ }^{2}$ Cerebrovascular and Skull Base Neurosurgery, LSUHSC Shreveport, \\ United States \\ ${ }^{3}$ Department of Neurosurgery, Royal Hobart Hospital, Affiliated to \\ University of Tasmania, Hobart, Tasmania, Australia \\ Indian J Neurosurg 2019;8:67-72
}

\begin{abstract}
Address for correspondence Anooja Abdul Salam, MBBS, MPH, Department of Neurosurgery, Royal Hobart Hospital, 48 Liverpool street, Hobart, Tasmania 7000, Australia (e-mail: abcanu@gmail.com).
\end{abstract}
Abstract
Keywords
- central sterilizing department
- Creutzfeldt-Jakob disease
- prion disease

This report refers to a rare case of a patient with suspected prion disease and the steps taken for the infection control measures in postsurgical management of a large sphenoid wing meningioma. Stringent measures are needed to prevent the transmission of Creutzfeldt-Jakob disease (CJD) to other patients or healthcare workers. The main concern, especially in a neurosurgical case, is the handling of highly infective tissue and hence the higher risk of disease transmission. This report provides guidance based on the experience in this case, as an aid to similar surgeries.

\section{Case Report}

A 69-year-old woman was admitted with a newly diagnosed large right sphenoidal wing meningioma. She had a background history of suspected Prion disease and was at low risk of developing Creutzfeldt-Jakob disease (CJD). She had been treated with human pituitary hormone for infertility in Australia's first computerized medical program, the Australian Human Pituitary Hormone Program, prior to 1986.

The patient underwent elective grade 2 Simpson excision of the meningioma without any complications. We present here the steps taken to safely proceed with a neurosurgical intervention in a patient with suspected Prion disease, specifically in the context of instrument availability and sterilization - Fig. 1 .

\section{Planning for Neurosurgery in a CJD Patient}

\section{Preoperative Planning}

1) Consultations held with the neurosurgeons within the department, the director of surgery, the CJD support group director, the codirector of the Australian CJD registry, and a member of the CJD incident panel; consultations also between infection-control teams at the Royal Hobart
Hospital and Westmead Hospital in Sydney (where a similar situation arose several years ago).

2) Detailed discussion with the theater in charge, nurse unit manager, anesthetic team, the patient, and family members.

3) One major preoperative issue was the availability of instruments. Instruments cannot be re-used and have to be incinerated or kept aside for the same patient.

4) Also, there were safety concerns with regard to the handling of higher infectivity tissue for the health professionals involved. Hence, the entire neurosurgical team involved with this case in theater were prepared well with regard to the infection control protocol for this case.

\section{Intraoperative}

1) All other cases were cancelled on the day of the surgery.

2 ) Instruments used for the procedure are detailed in $\boldsymbol{- F i g . ~} \mathbf{2}$.

\section{Postoperative (Sterilization)}

1) Sterilization and storage-central sterile supply department (CSSD):

The nurse unit manager, infection prevention \& control unit, created a plan based on the CJD infection control 

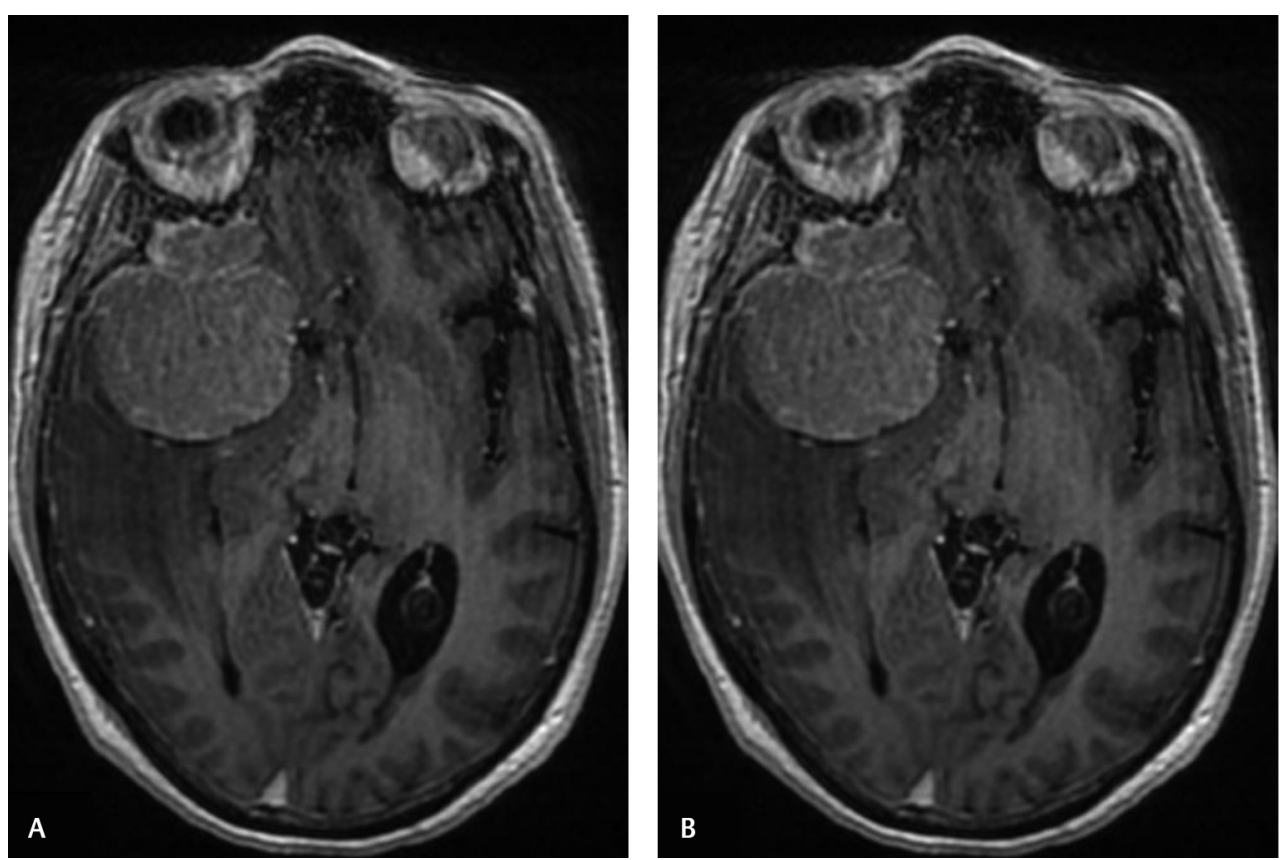

Fig. 1 MRI brain $(\mathrm{T} 1+\mathrm{C})$ showing $(\mathbf{A})$ large extra-axial mass arising from the right greater wing of the sphenoid bone. (B) Post excision of the large right sphenoid wing meningioma. MRI, magnetic resonance imaging.

guidelines in consultation with the heads of the theater and the central sterilizing department (CSD).

2. All instruments were stored in theater for future use for this patient after sterilization.

The management plan for reprocessing of the instruments followed the seven-step detailed protocol of the CJD infection control guidelines 2013 , which is briefly summarized below. ${ }^{1}$

STEP 1: Transfer of reusable instruments to the CSD. ${ }^{1}$

STEP2: Initial management of instruments ${ }^{1}$

- Cleaning of instruments with ionic detergent

STEP3: Waste management ${ }^{1}$

After the initial cleaning, the operator disposes the soiled PPE (personal protective equipment) in the cytotoxic bin marked as HIGH-RISK, places it in the waste collection area, and notifies environmental services to collect it as soon as possible.

- The instrument transport boxes are disinfected with bleach (as per the guidelines) and subsequently flagged for incineration.

STEP 4: Management after initial cleaning and before sterilization. ${ }^{1}$

- Instruments are handled wearing PPE always and checked for dryness.

- Once clean, they are manually dried and then left to dry fully in the green bean trays and "isolated" in the macrowash area which will be closed to other activity.

STEP 5: Cleaning of macro area ${ }^{1}$

- Disinfected with bleach at 20,000 ppm. STEP 6: Packing for sterilization ${ }^{1}$
- A clearly defined area in the approved space is used for packing. Clean dry instruments are transferred to the packing room where a spare wrap is placed on the surface, a wrap required for the pack is placed on the top, and packing done as per normal practice.

STEP 7: Sterilization and postmanagement ${ }^{1}$

- The instruments are sterilized as a separate load. The packs are handled carefully to prevent crossover and bundled together in a sealed peel pack, with clear labeling of patient identifying stickers, and subsequently placed in a location appropriate for storage of sterile items, but separated from general trays and instruments, for future use for this patient.

\section{Discussion}

Creutzfeldt-Jakob disease is a fatal human Prion disease belonging to the transmissible spongiform encephalopathies (TSEs) ${ }^{1}$. CJD occurs in familial, sporadic, and acquired (iatrogenic and variant CJD) forms, ${ }^{1}$ and this condition is caused by a pathological accumulation in the brain of an aberrant form of a normal cell surface glycoprotein or Prion Protein (PrP). ${ }^{1}$

Given that there is presently no test available to confirm the presence of CJD, the decision to implement additional procedures for equipment reprocessing is based on risk assessment tools which classify the spectrum of infectivity of the tissues exposed, and by identifying patients with definite versus potential risk of CJD transmission. ${ }^{1}$

The mode of transmission is via instruments contaminated with the central nervous system tissue or contaminated tissue implants or products like dura mater grafts, corneal grafts or pituitary products. ${ }^{1}$ Prion protein is the infective agent in CJD and is resistant to routine reprocessing. 
CRANIOTOMY TRAY

TRAY NO.

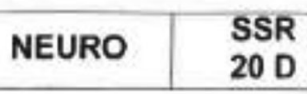

\begin{tabular}{llll}
\hline CLEANING: TUNNEL WASHER; & WRAPPING: DOUGLAS BEAN & STERILISING: & STEAM \\
SPECIALIST AREA & TRAY; SMARTFOLD STERILISING & \\
& WRAP \& LINER & \\
& &
\end{tabular}

\section{TIPS CHECKED FOR ALIGNMENT OR DAMAGE}

\begin{tabular}{|c|c|c|}
\hline$\frac{8}{\frac{2}{0}}$ & Cat. No. & INSTRUMENTS \\
\hline 1 & & Handle, BP, No.15 \\
\hline 2. & & Handle, BR.No. 4 \\
\hline 3 & & Forcep, Dissecting, Adson's Toothed \\
\hline 4 & & Forcep, Bayonet, Plain \\
\hline 5 & & Forcep, Bayonet, with Gold Handle \\
\hline 6. & & Forceps, Dissecting, Gillies, Toothed \\
\hline 7 & & Forceps, Dissecting, Two Toothed \\
\hline 8 & & Forceps, Dissecting, Penfields, Plain \\
\hline 9 & & Scissors, Tenotomy Tip Protect \\
\hline 10 & & Scissors, Metzenbaum \\
\hline 11. & & Scissors, Mayo, Straight \\
\hline 12. & & Scissors, Curved, Fine Pointed, Blunt \\
\hline s. & & Forceps, Artery, 5 Gurved \\
\hline 14 & & Forceps, Antery, Mosquito (Martin). \\
\hline 15 & & Forceps, Dandy, Straight \\
\hline 16 & & Applicators, Clip, Raney \\
\hline 17 & & Holder, Needle, Mayo-Hegar, Small \\
\hline 18 & & Holder, Needle, Mayo-Hegar, Fine \\
\hline & 14148,18 & Holder, Needle \\
\hline & 14413.19 & Twister, Wire \\
\hline 19 & & Holder Sponge. \\
\hline 20 & & Clp, TowelEdea Small \\
\hline & & Clip, Towel, Edna, Large \\
\hline 21 & & Pins, Mayyield tip protect (on small green bean) \\
\hline 22. & & Clips, Blue \\
\hline 24. & & Retractors, Rake \\
\hline 25 & & Retractors, Brain, Assorted - Straightened \\
\hline 26 & & Retractors, Langenbeck, Small \\
\hline 27 & & Retractors, Langenbeck, Large \\
\hline 28 & & Hook, Sharp - Tip Protect \\
\hline
\end{tabular}

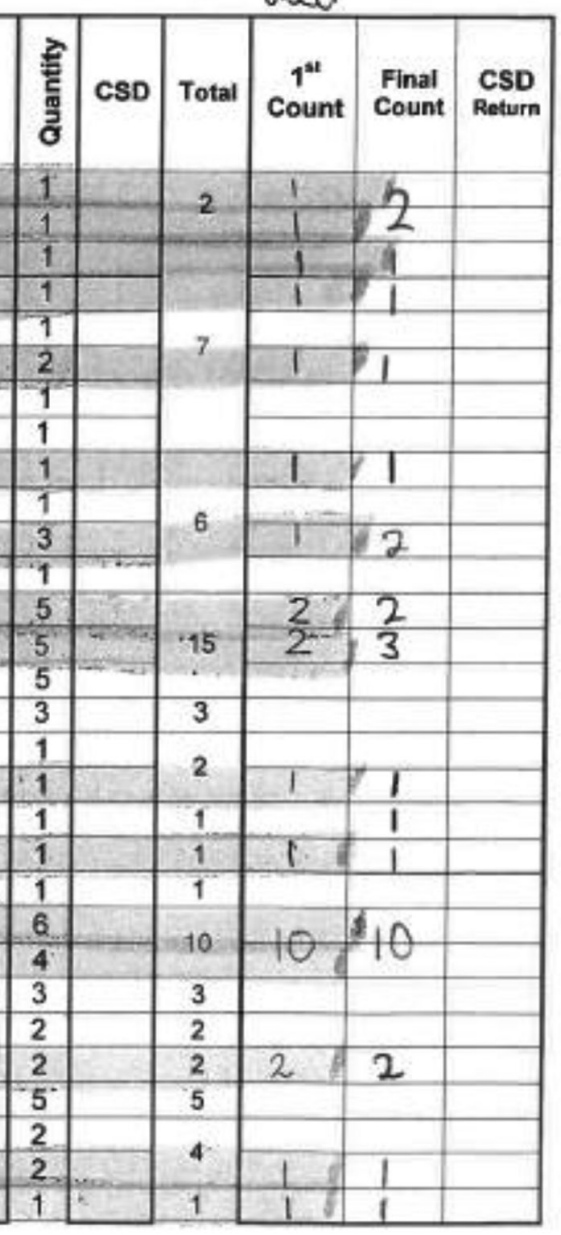

\begin{tabular}{|c|c|c|c|c|c|c|c|c|}
\hline $\begin{array}{l}\frac{0}{0} \\
\frac{c}{a}\end{array}$ & Cat. No. & INSTRUMENTS & 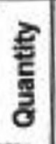 & CSD & Total & $\begin{array}{c}1^{\text {th }} \\
\text { Count }\end{array}$ & $\begin{array}{l}\text { Final } \\
\text { Count }\end{array}$ & Return \\
\hline 30 & & Elevator Periosteal Sharp. & 1 & & 2 & 1 & 1 & \\
\hline 31 & & Elevator. Periosteal Blunt & 1 & & & 7 & 1 & \\
\hline 29. & & Retractor, Watson Cheyne & 1 & & 1 & & & \\
\hline 33 & & Dissectar Penfields No. 1 & 1 & $x^{\circ}$ & 9 & & n & \\
\hline 32 & & Dissector, Ponfields No. 4 & 1. & & & + & 71 & \\
\hline 34$]$ & & Sucker Neuro. Size 6 & 2 & & & & & \\
\hline & & Sucker. Neuro, Size 8 & 2 & & 8 & 8 & 6 & \\
\hline & & Sucker Neuro Size 10 & 2 & & & & 8 & \\
\hline & $x=$ & Sucker. Neuro, Size 12 & 2 & & & & & \\
\hline & & Stillette, Size 6 (on small bean tray) & 1 & & & & & \\
\hline & & Stillette, Size 8 (on small bean tray) & 1 & & 4 & & l & \\
\hline & & Stiliette Size 10 (on small bean tray) & 1 & & & 4 & I & \\
\hline & & Stillette, Size 12 (on small bean tray) & 1 & & & & & \\
\hline 136 & & Nibbler, Pennybacker & 1 & & i & 1 & 1 & \\
\hline so & 2126002 & Mini Ruskin Bone Rongeur $2 \mathrm{~mm}$ & 1. & & 1 & 1 & 1 & \\
\hline 38 & $220-0019$ & Handle Screwdriver Osteomed & 1. & & 1 & $T$ & 1 & \\
\hline 39 & $220-0061$ & Bit. Osteomed (on small bean tray) & 1. & & 1 & $T$ & 1 & \\
\hline
\end{tabular}

(continued) 
(continued)

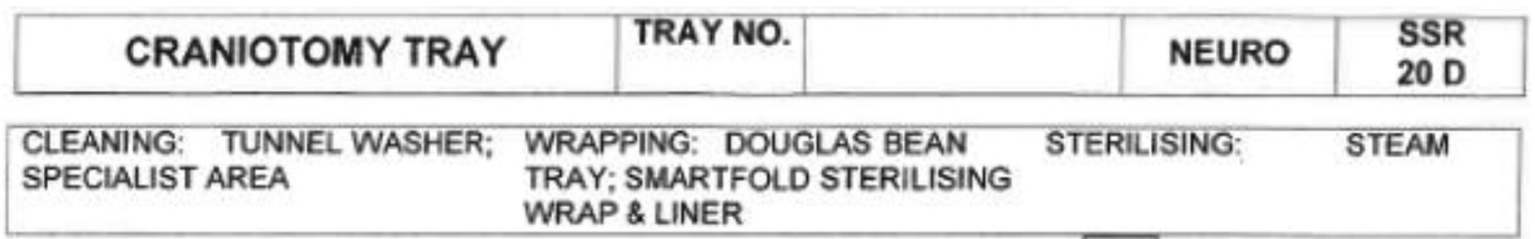

\section{TIPS CHECKED FOR ALIGNMENT OR DAMAGE}

\begin{tabular}{|c|c|c|c|c|c|c|c|c|}
\hline $\begin{array}{l}\frac{8}{0} \\
\frac{2}{2}\end{array}$ & Cat. No. & INSTRUMENTS & 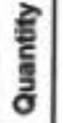 & cso & Total & $\begin{array}{c}1^{\text {th }} \\
\text { Count }\end{array}$ & $\begin{array}{l}\text { Final } \\
\text { Count }\end{array}$ & $\begin{array}{c}\text { CSD } \\
\text { Return }\end{array}$ \\
\hline 1 & & Hande, BP, No,5 & 1 & & 12 & 1 & $h$ & \\
\hline 2 & & Handle, BR.No.4 & 1 & & $1=$ & & 2 & \\
\hline 3 & & Forcep. Dissecting Adson's Toothed & 11 & & & 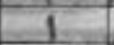 & a & \\
\hline 4. & & Forcep, Bayonet, Plain & 1 & & 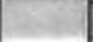 & I & 1 & \\
\hline 5 & & Forcep, Bayonet, with Gold Handle & 1 & & 7 & & & \\
\hline 6. & & Forceps, Dissecting, Gilies, Toothed & 2 & & I & I & 1 & \\
\hline 7 & & Forceps, Dissecting, Two Toothed & 1 & & & & & \\
\hline 8 & & Forceps, Dissecting, Penfields, Plain. & 1 & & & & & \\
\hline 9 & & Scissors, Tenotomy Tip Protect & 1 & & 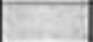 & I & 1 & \\
\hline 10 & & Scissors, Metzenbaum & 1 & & 0 & & & \\
\hline (11.) & & Scissors, Mayo. Straight & 3 & & 6 & $\mathrm{~T}$ & 2 & \\
\hline 12 & -2 & Scissors, Curved, Fine Pointed, Blunt & 1 & & & & & \\
\hline 3. & & Forceps, Artery, 5 Curved & 5 & 5 & & 2 & 2 & \\
\hline 14 & & Forceps, Artery, Mosquito (Martin). & 5 & & 15 & 2 & 3 & \\
\hline 15 & & Forceps, Dandy, Straight & 5 & & & 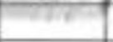 & & \\
\hline 16 & & Applicators, Clip, Raney & 3 & & 3 & & & \\
\hline 17. & & Hoider, Needle, Mayo-Hegar, Small & 1 & & $?$ & & & \\
\hline 18 & & Holder, Needle, Mayo-Hegar, Fine & 1 & & 2 & I & 1 & \\
\hline & 14148,18 & Holder, Needle & 1 & & 1 & & $\mathbf{I}$ & \\
\hline & 14413.19 & Twister, Wire & 1 & 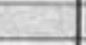 & 1 & 1. & 1 & \\
\hline 19 & & Holder Sponge.... & 1 & & 1 & & & \\
\hline 20 & $\omega$ & 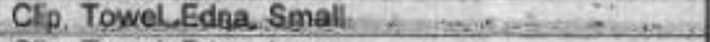 & 6. & & & & 10 & \\
\hline & . & Clip, Towel, Edna, Large & 4 & & 10 & & $H$ & \\
\hline 21 & & Pins, Mayvield tip protect (on small green bean) & 3 & & 3 & & & \\
\hline 22 & & Clips, Blue & 2 & & 2 & & & \\
\hline 24 & a & Retractors, Rake & 2 & & 2 & 2 & 2 & \\
\hline 25 & & Retractors, Brain, Assorted - Straightened & 5 & & 5 & & & \\
\hline 26 & & Retractors, Langenbeck, Small & 2 & & 4. & & & \\
\hline 27 & t5 & Retractors, Langenbeck, Large & 2. & & 4 & L & 1 & \\
\hline
\end{tabular}

$$
\begin{array}{ll}
\text { metal Jug } \times 1 & \times 1 . \\
\text { Mayfield Brace } \times 1 & \times 1 \\
\text { Ref: } A-1059
\end{array}
$$

Fig. 2 Copy of the checklist of instruments used for the procedure. 
Hence, additional sterilizing procedures are devised to prevent the risk of transmission. ${ }^{1}$

Chemicals like anionic detergents, hypo chlorites, harsh acids, and alkalis have some activity against Prion disease. ${ }^{1}$ However, the major concerning factor in these cases is that multiple reprocessing steps will only reduce infectivity. ${ }^{1}$ There is no established method found yet to fully sterilize the instruments, so that they can be reused in other patient's safely. ${ }^{1}$ Hence, it is recommended to use single-use instruments wherever possible, without compromising on patient care ${ }^{1}$.

The case discussed here is an iatrogenic CJD, secondary to receiving human pituitary hormone product for infertility. This is considered as a low-risk case since the patient has only a potential risk of CJD transmission. It is not a definite risk; however, the necessary preparations are cumbersome.

The procedures outlined here are a guide for similar surgical situations. Even though this a rare scenario, being well-prepared for these situations will help significantly, especially in cases requiring emergency surgery. Planning for instruments required for the surgery which can be incinerated, is a major challenge. Also, extensive preparation of the entire team in the theater with regard to the infection control measures preoperatively helped the staff involved significantly in dealing with a rare scenario like this.

We were fortunate since this patient was stable and we had adequate time to consult with multidisciplinary teams and prepare for the situation in a timely manner. All the instruments used have been labeled and stored separately for future use in this patient if required.

\section{Conclusion}

The large sphenoid wing meningioma found in this patient with suspected Prion disease was successfully and safely managed by timely and methodical intervention. The steps taken for proceeding with the surgical management and aftercare may be useful for similar cases in future.

\section{Conflict of Interest}

None declared.

\section{Acknowledgment}

We would like to thank Rachel Thompson, Nurse Unit Manager, Infection Prevention \& Control Unit, for creating a sterilization and storage plan, based on the CJD infection control guidelines, for the entire neurosurgical team involved in this case.

\section{References}

1 Creutzfeldt-Jakob disease. Available at: http://www.health.gov. au/internet/main/publishing.nsf/Content/3A968399995CFCE5CA257BF000211E32/\$File/CJDInfectionControlGuidelinesJan2013.pdf Published January 2013. Updated April 15, 2013. Accessed March 25, 2019 